\title{
Infrastructural Systems toward the Valorisation of the History of Architecture: the Case of the Metro-Art in Naples
}

\author{
Alessandro Castagnaro ${ }^{1, a}$ \\ ${ }^{1}$ Department of Architecture, 402 Toledo Street Naples, Italy \\ aalessandro.castagnaro@unina.it
}

Keywords: Urban Archaeology, Contemporary Architecture, Mobility Infrastructures.

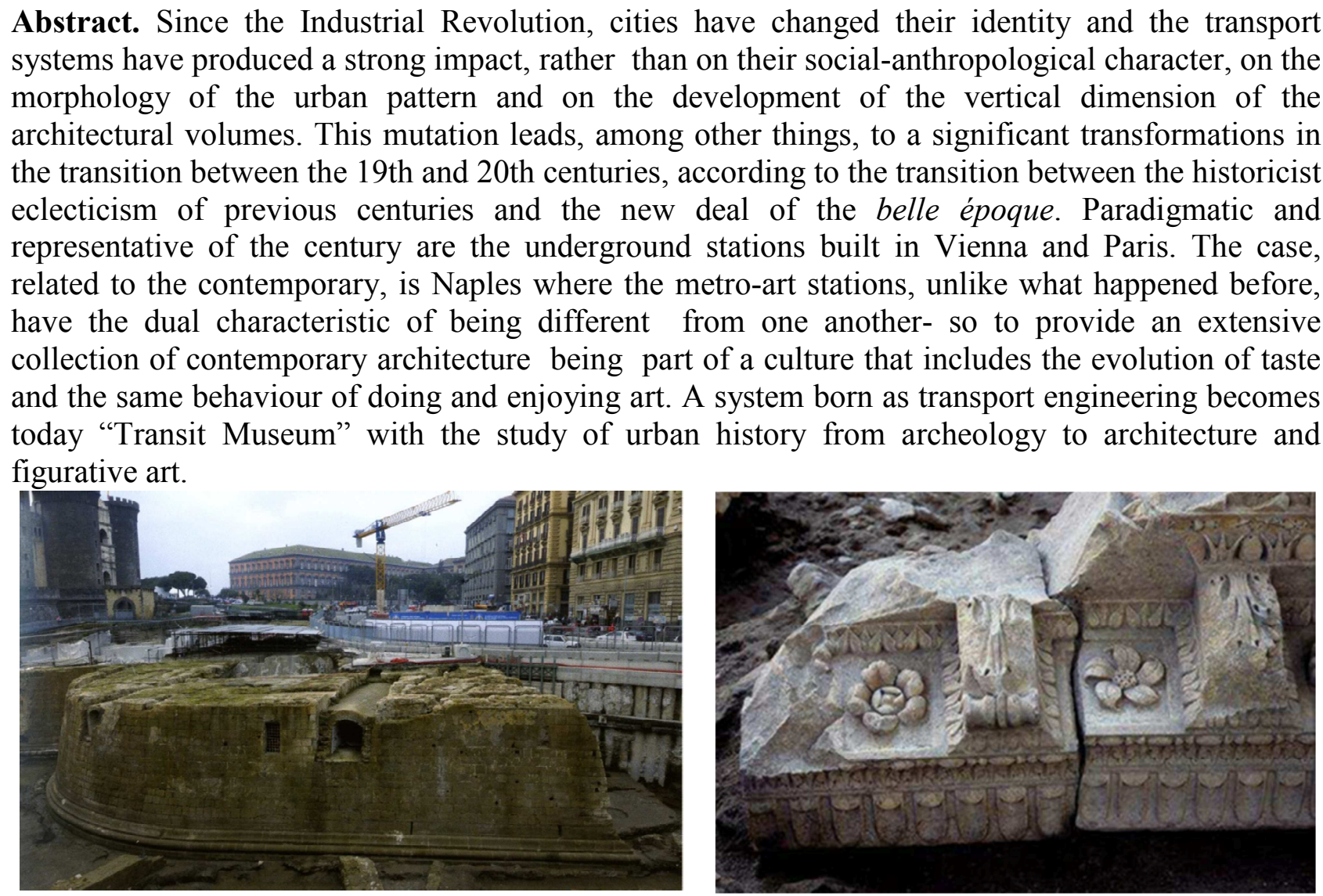

Fig. 1-2 .Torrione dell'Incoronata and other archaeological sites discovered during the Metro excavations (Courtesy

Rassegna ANIAI)

\section{The Industrial Revolution as the boost of the engineering architecture}

Since the Industrial Revolution, cities have changed their identity and the transport systems have produced a strong impact, rather than on their social-anthropological character, on the morphology of the urban pattern and on the development of the vertical dimension of the architectural volumes. The city as a whole begins a transformation process with an increasingly evident acceleration due to the societal and economics evolution. A kind of dynamism can be appreciated following the development of artistic avant-gardes such as the Futurism and its artworks which could be interpreted as part of the radical transformation of urban areas [1,2]. The movement born with the incentive of the literary manifesto written by the Italian poet Tommaso Marinetti, published on "Le Figaro" February 20,1909, which begins" We affirmed that the world's magnificence has been enriched by a new beauty: the beauty of speed".

The rail transport systems, with the urban and extra urban railways and funiculars, have strongly influenced the expansion of the city and the relationships between the inner city and the surroundings, favouring the metropolitan dimension between new towns, suburbs and the historical Urbis [3,4]. (Fig. 3,4) 

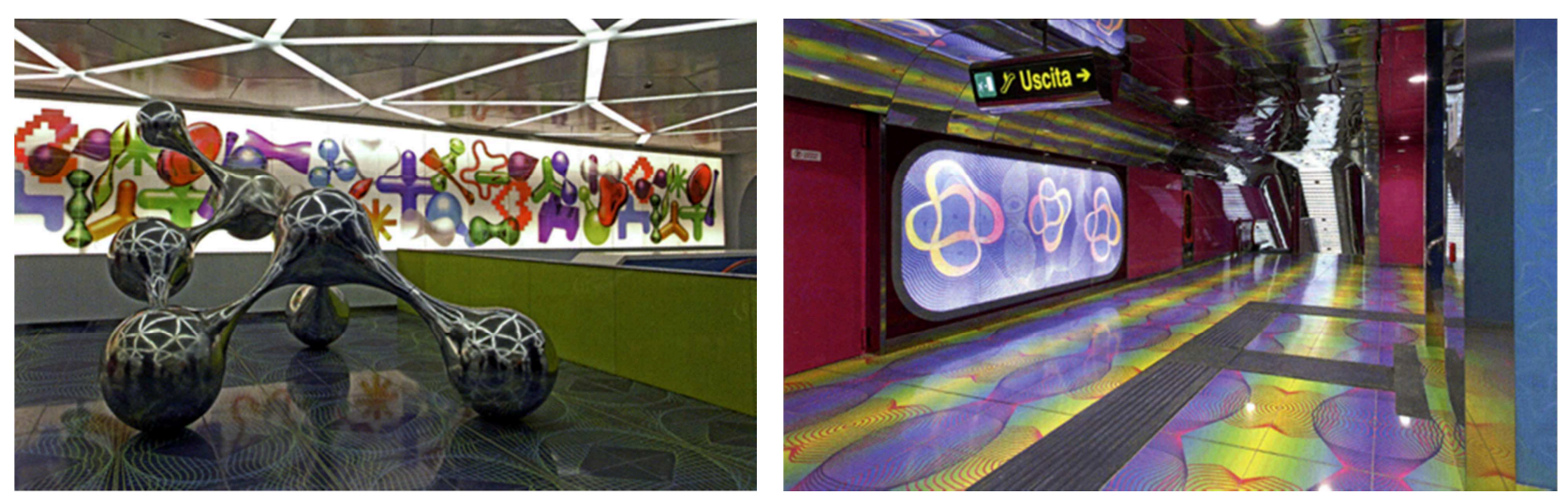

Fig. 3,4. Metro of Naples (line n. 1) University Station designed by Karim Rashid (Courtesy Rassegna ANIAI)

This mutation leads, among other things, to a significant transformations in the transition between the 19th and 20th centuries, according to the transition between the historicist eclecticism of previous centuries and the new deal of the belle époque. Paradigmatic and representative of this period are the subway stations designed by Otto Wagner (1841-1918) in Vienna, starting in 1894 [5]. Wagner was appointed advisor for the Municipality and artistic advisor of the City Traffic Management Committee which designs the whole railway network both in surface and underground. Between 1895 and 1900 four railway lines were built for a total of forty-five kilometers and thirty stations. Another important example can be found in Paris, focusing on the notable Art Nouveau projects developed by Hector Guimard (1867-1942) [6]. The Guimard experience has been considered paramount both in terms of absolute architectural and artistic values and in terms of the dissemination of those artistic values on a large-scale, even with the limited availability of economic resources. In particular, the design of the entrance kiosks of the Paris metro stations have been universally recognized as successful expressions of the Paris culture: the iron structures and the polychrome glass are brands of the city style. In Italy, in recent times (19641969), the experience of the Milan Metro - designed by Franco Albini and Franca Helg, in collaboration with Antonio Piva and TEKNE for supervision of work - can be discussed [7] The project - which moves within the main structures already built, so with reduced operating margins for what concern the routes and the size of the space - includes shops, service equipment, station services, fixed furniture, lighting, materials, every architectural details and the whole corporate image that, by explanatory panels inside of the trucks until the surface signs, will feature the second metro line, conduct the project at a uniformity and recurrence pattern, of the individual stations.

According to this reflections, the paper discusses the experience of the so called Metro-art developed in Naples at the present times in order to integrate the mobility function with the need of exhibiting contemporary art items and disseminating cultural awareness.

\section{The case of Metro-art of Naples : urban archeology, contemporary architecture and Transit Museum}

The paper tackles the recent case of the Naples Metro Line 1, the largest and most significant accomplishment over the last two decades in the city [8]. In the early 90s - the city council was chaired by the Major Antonio Bassolino - Naples went through twists and turn, more for the media 


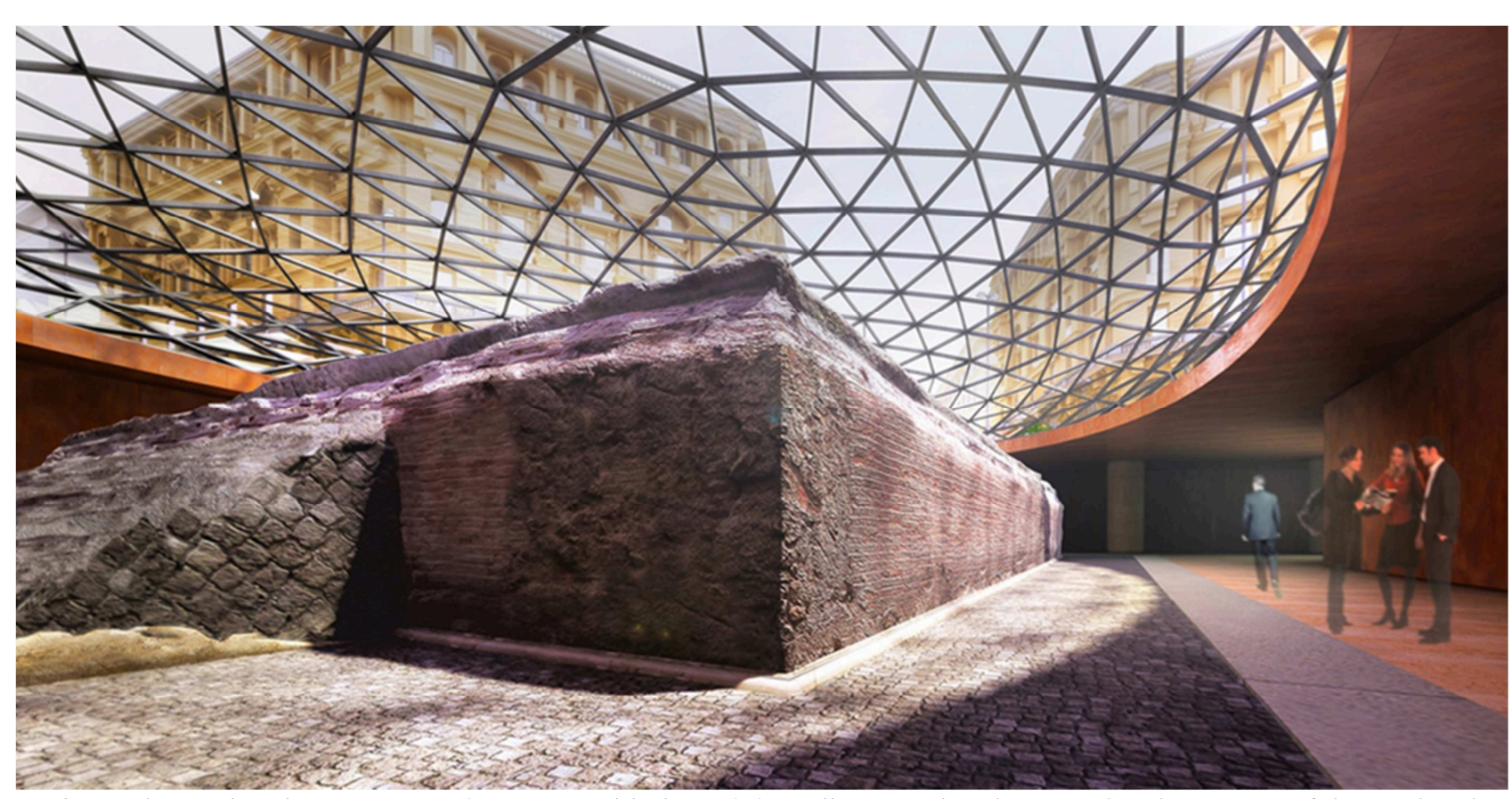

Fig. 5 The Station in piazza Nicola Amore, with the stilobate discovered underground and now part of the steel and glass structure.

than for urban and architectural events. (Fig. 5)

The main issues of the city were congestion and decay of the historical centre on the one hand and abandonment and decay of the social housing settlements in the suburbs on the other. Urban mobility at metropolitan level has been considered the possible engine for the needed redevelopment and the rehabilitation of degraded and abandoned urban territory.

Originally, the metropolitan system of railways was considered mainly an engineering activity, without any relationship with the urban planning trajectories and the architectural aspects. The latter were neglect as the architectural elements were limited exclusively to the production of urban furnishings or stations or public parks and squares, without any participation of local communities, stakeholders and professionals.

The projects developed were not the result of public competitions but assigned to invited architects of the international star system; in some cases, the project has dropped from above without any relationship with the social, cultural and environmental context [9]. Nowadays, a new trend can be recognized. The Metro system involves major infrastructural works and relevant engineering excavations which have enlightened important archaeological sites, discovered underground in the city centre of Naples. The world-class historical centre of Naples, recognized as UNESCO site, has been enriched by the outlook on the ancient cultural heritage, offering an updated reading of the ancient city.

We are talking about the sanctuary of Neapolitan Isolimpics games, the Angevin district in the surroundings of Castelnuovo. The projects of the new metro-stations in the area have started a process of relevant experiences of urban archaeology, by recognizing the values of the historical stratification of the city of Naples [10]. The stations, unlike what happened before, have the dual characteristic of being different from one other - so as to provide an extensive repertoire of contemporary architecture - and being part of a cultural experience which embraces the evolution of the sensorial experiences of enjoying archaeology and contemporary art. A mobility infrastructure that has been born as a transport engineering, has become today a Transit Museum or, as Achille Bonito Oliva said a Compulsory Museum. As a matter of fact, under his artistic direction, in most stations were placed sculptures, mosaics, panels, photographs, elements of contemporary art of some of the greatest artists as Ousmane Ndiaye Dago, Nicola de Maria, Sol Lewit, Bob Wilson, William Kentridge, Emilia Kabakov, Shirin Neshat, Oliviero Toscani, Mimmo Jodice and many others. Scattered along covered and uncovered paths that do not constitute a simple embellishment 
of the moment but, as the same Oliva argued, are "structures that interacting with that pre-existing, which stumbling the gaze of people walking through, gaze carefully, and sometimes carelessness". (Fig. 5,6)

In a place typically characterized by rapidity and speediness, the juxtaposition of museum and
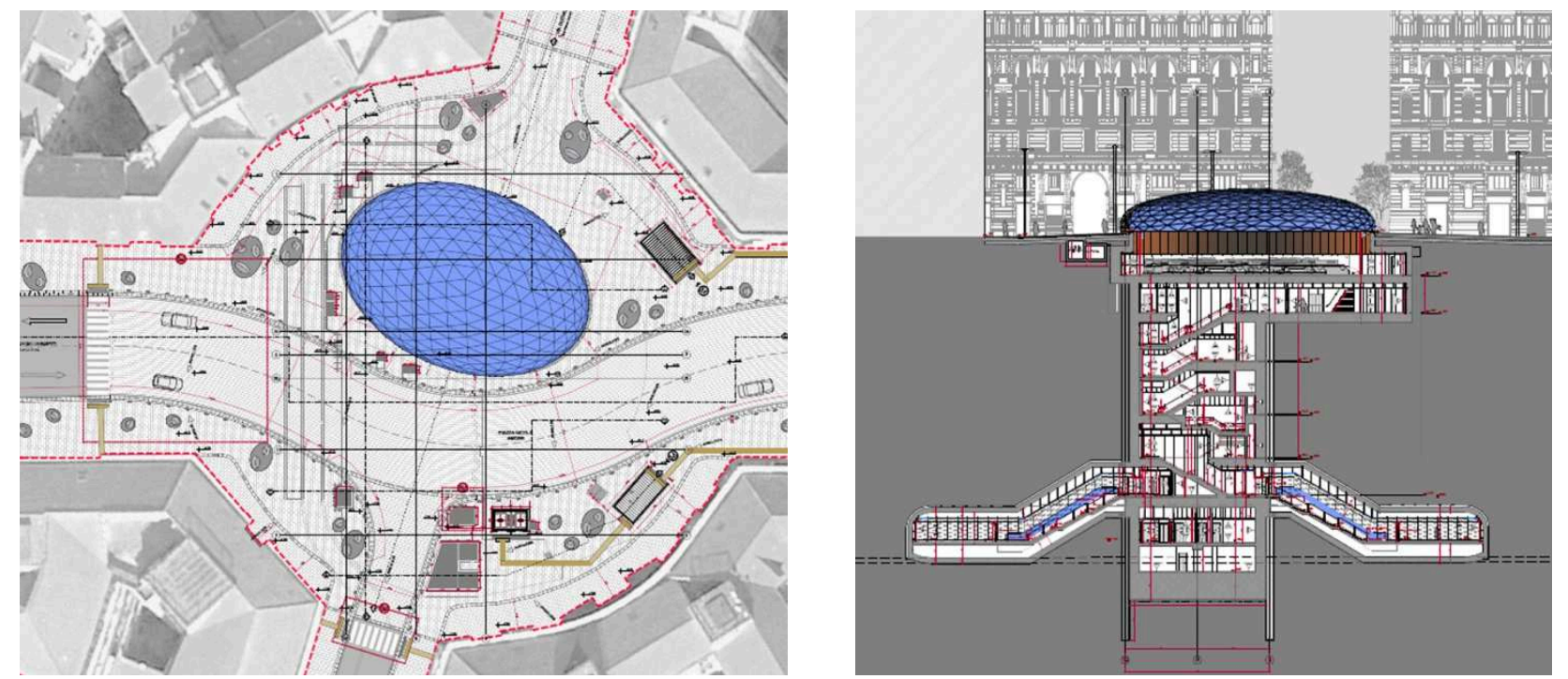

Fig. 5,6. The Station in piazza Nicola Amore. Project by Massimiliano Fuksas (Courtesy Rassegna ANIAI)

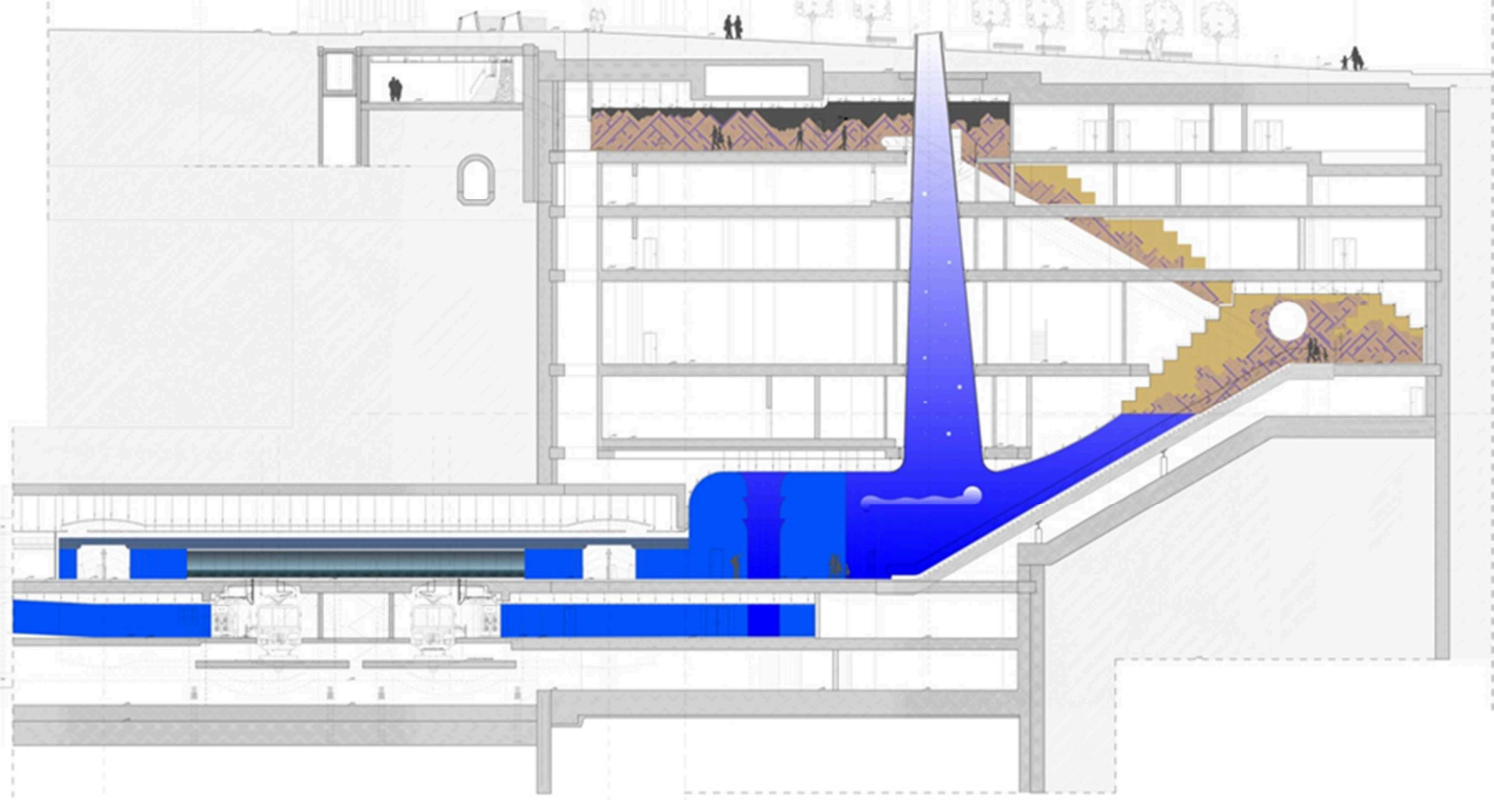

Fig. 7 Toledo Station designed by Oscar Tusquets (Courtesy Rassegna ANIAI)

infrastructure can be appreciated, requiring reflection, contemplation, critical judgment; those mental activities which apparently are in antithesis with the compulsory rhythms of the mobility nodes, could be defined successfully as new human attitudes and behaviours [11]. (Fig. 7)

Thanks to the interventions in the Metro of Art, the historic city has opened in a new way to the contemporary architecture: lying in front of a kind - in the best sense of the term - collection of 
stations widespread in the heterogeneity of current architectural languages. It's true that even here the choices of the signature architectures are questionable and do not participate, without any kind of design competition and without participation of local communities, as it is also true that the choice was deliberately excluded any local designer. Among the most representative project dropped in the urban reality should mention Piazza Municipio made by Alvaro Siza and Eduardo Souto de Moura [12] whose works are being performed, Piazza Garibaldi, inaugurated on December 2013 is one that strongly effects on urban design. Designed by the French architect Dominique Perrault, connects Piazza Garibaldi with the Central train station [13]; the cooperation between the atelier Mendini and the Iraqi artist Karim Rashid gave rise to the design of the station Piazza Bovio University [14]. Oscar Tusquet Blanca has performed the project of the Toledo station - with the second exit in the Piazza Montecalvario - providing the first infrastructure within the regular pattern of the military settlement of the 17th century called Quartieri Spagnoli [16]. Gae Aulenti has designed in the Dante Station in the former Foro Carolino, now Piazza Dante, modifying the layout of the square and the station below. The Museum station with the access beyond the National Museum and the connection in Piazza Cavour can be considered an engine of the urban redesign. Finally, to limit the analysis to only those made in the historic centre of the city should be mentioned the discussed station of Piazza Nicola Amore - Duomo designed by Massimiliano Fuksas, which on one hand represents another case of urban infrastructure related to archaeology, thanks to the excavations and discoveries, on the other hand feeds misgiving for the forced interruption provided to the axis of the so called Rettifilo, boulevard built according to the Haussmann memory [16]. (Fig. 8)

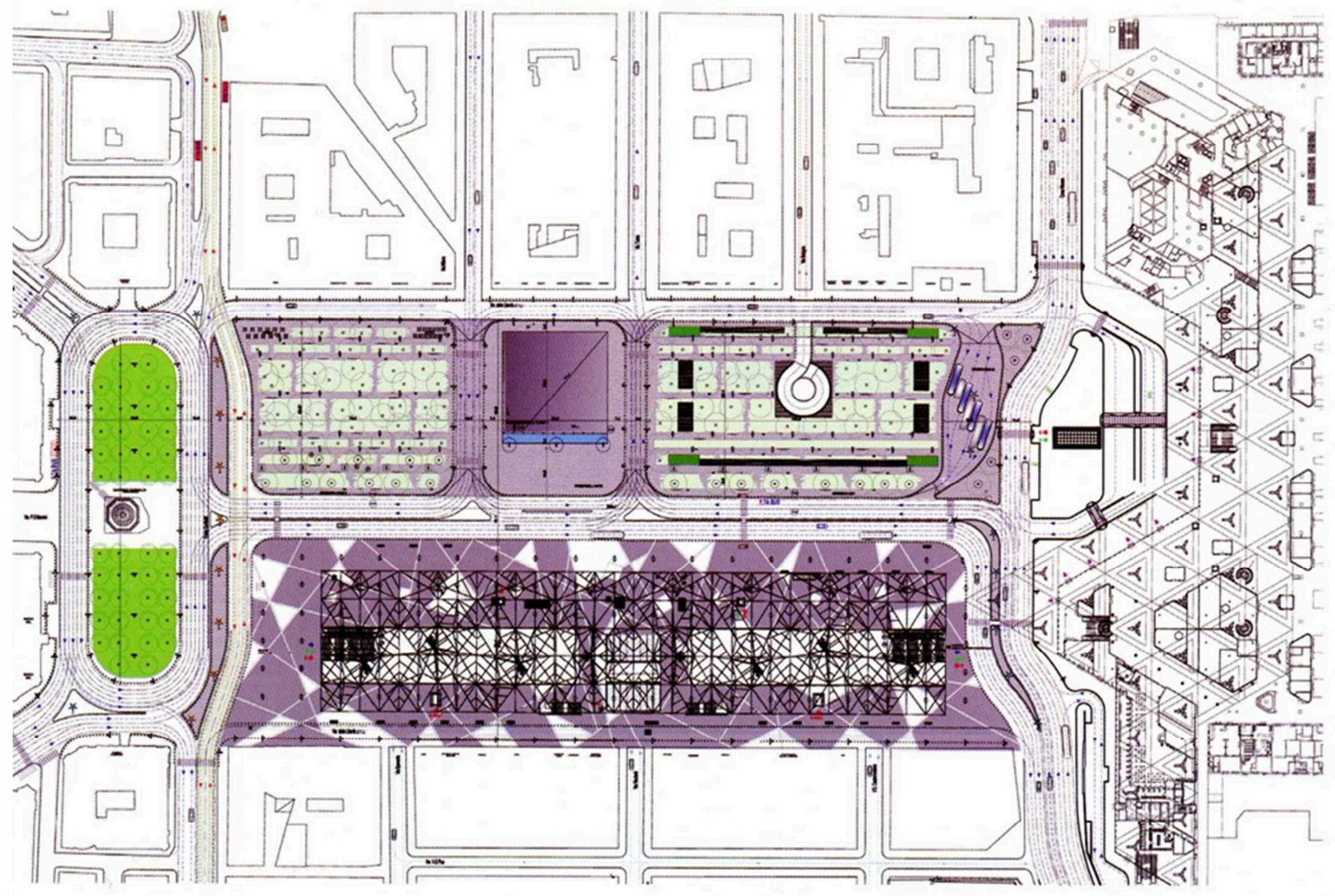

Fig.8. Piazza Garibaldi Station. Designed by Dominique Perrault. (Courtesy Rassegna ANIAI)

\section{Conclusions}

The Naples experience is very rich in terms of relationships between a mobility infrastructure, architecture masterpieces, archaeological sites and contemporary art. Those relationships could be considered consistent with the valorisation of the cultural heritage and the dissemination of 
contemporary art and architectures. Unfortunately, the success of this cultural process has been reduced by the lack of participation of local communities, professionals and economic stakeholders in the decision process. Nevertheless, the Metro had and is taking a significant role for the Neapolitan culture, opening new perspectives in an area which generally resist to new experiences. It has started a process of interpreting the old and the new relationship always extremely confrontational where even denied and obstructed, a relationship that affects the new contemporary architecture in historic centre, but it also allows an interpretation and an understanding of contemporary art that is now no longer closed in galleries and/or museums but open to places of transit to everyone, assuming a function which became informative and didactic.

\section{References}

[1] M. De Micheli: Le Avanguardie artistiche del Novecento, Milano, Electa (1966)

[2] A. Castagnaro: Verso l'Architettura contemporanea, Napoli, Paparo Ed (2012)

[3] R. De Fusco: Storia dell'architettura contemporanea, Roma-Bari, Laterza (2000)

[4] P. Sica: Storia dell'urbanistica L'Ottocento, Roma-Bari, Laterza (2000)

[5] T. Robert, Otto Wagner, Roma-Bari, Laterza (2006)

[6] J. Tricoire: Un siècle de métro en 14 lignes. De Bienvenüe à Météor, Paris, Éditions La Vie du Rail (1999)

[7] F. Bucci: Franco Albini e la Scuola Milanese, Milano: Electa (2009)

[8] AA.VV.: La Metropolitana di Napoli. Nuovi spazi per la mobilità e la cultura, Napoli: Electa (2000)

[9] S. Paoli (a cura di): Le Stazioni dell'Arte, Giannini Editore, Napoli (2004)

[10] B. Gravagnuolo: Metro.polis in B. Gravagnuolo, Napoli dal Novecento al futuro, Electa Napoli (2008)

[11] E. Cascetta: Il sistema della Metropolitana regionale in Campania, Ingegneri, Ordine di Napoli, Novembre-Dicembre (2007)

[12] E. Cascetta, B. Gravagnuolo (edited by): Le Metropolitane e il futuro delle città, Napoli: CLEAN (2014)

[13] AA.VV.: Metropolis, La sfida del Trasporto su ferro a Napoli e in Campania, Partner iniziative in the context of the $10^{\circ}$ International Architecture Exhibition, Biennale di Venezia. Abitare, vol. 464 (2006)

[14] D. Giampaola: Archeologia e progetto, Rassegna ANIAI vol. 3 (2012)

[15] A. Castagnaro: Napoli, le Metropolitane d'Arte e le interviste a Renato De Fusco, Vittorio Di Pace, Sandro Raffone, Benedetto Gravagnuolo, Arcangelo Cesarano in Punti di Vista C. Celestino, D. Durante, R. Gliubizzi, F. Rinaldi, Rassegna ANIAI vol. 1 (2003)

[16] A. Bonito Oliva: Il museo obbligatorio in Dossier. La Metropolitana di Napoli, Rassegna ANIAI 1(2011)

[17] A. Siza, E. Souto de Mura: Stazione di Piazza Municipio in Dossier. La Metropolitana di Napoli, Rassegna ANIAI vol. 1-2 (2012)

[18] R.Amirante: Metropolitana Garibaldi. Come trasformare una piazza in tante piazze in Dossier. La Metropolitana di Napoli, Rassegna ANIAI vol. 4 (2011)

[19] G. D’Amato: La stazione della metropolitana di Piazza Bovio in Dossier. La Metropolitana di Napoli, Rassegna ANIAI vol. 2 (2011)

[20] O. Tusquets Blanca: La stazione Toledo-Montecalvario in Rassegna ANIAI 3 (2011)

[21] U. Carughi: Valori storici, urbani e architettonici strettamente interconnessi, Rassegna ANIAI vol. 1-2 (2012) 